\title{
Anne-Pascale Pouey-Mounou, Panurge comme lard en pois. Paradoxe, scandale et propiété dans le «Tiers Livre»
}

\section{Michele Mastroianni}

\section{(2) OpenEdition \\ Journals}

\section{Edizione digitale}

URL: http://journals.openedition.org/studifrancesi/2109

DOI: 10.4000/studifrancesi.2109

ISSN: 2421-5856

\section{Editore}

Rosenberg \& Sellier

\section{Edizione cartacea}

Data di pubblicazione: 1 aprile 2014

Paginazione: 129-130

ISSN: 0039-2944

\section{Notizia bibliografica digitale}

Michele Mastroianni, « Anne-Pascale Pouey-Mounou, Panurge comme lard en pois. Paradoxe, scandale et propiété dans le «Tiers Livre» », Studi Francesi [Online], 172 (LVIII | I) | 2014, online dal 01 avril 2014, consultato il 18 septembre 2020. URL : http://journals.openedition.org/studifrancesi/2109; DOI : https://doi.org/10.4000/studifrancesi.2109

\section{Questo documento è stato generato automaticamente il 18 settembre 2020.}

\section{cc) $($ ) $\ominus$}

Studi Francesi è distribuita con Licenza Creative Commons Attribuzione - Non commerciale - Non opere derivate 4.0 Internazionale. 


\title{
Anne-Pascale Pouey-Mounou, Panurge comme lard en pois. Paradoxe, scandale et propiété dans le «Tiers Livre»
}

\author{
Michele Mastroianni
}

\section{NOTIZIA}

ANNE-PASCALE POUEY-MOUNOU, Panurge comme lard en pois. Paradoxe, scandale et propiété dans le «Tiers Livre», Genève, Droz, 2013 («Travaux d'Humanisme et Renaissance», n. DXIII), pp. 588.

1 Fra i numerosi studi di questi ultimi anni su problematiche centrali e spinose relative e ne ricordiamo solo alcune - alla questione del senso, della costruzione retorica, dei registri linguistici, delle fonti, delle dinamiche diegetiche della scrittura rabelaisiana ecc., si può ora annoverare l'importante monografia di Pouey-Mounou, lavoro originale e fitto che fornisce nuovi dati sulla poetica di Rabelais, secondo una prospettiva di interesse critico-filologico che si concentra, in particolare, sul Tiers Livre. Partendo da un quadro storico-politico, permeato dalle forti tensioni spirituali, quelle stesse che danno vita alla Riforma e alla Controriforma, l'A. costruisce il suo discorso centrandolo sul personaggio di Panurge, figura provocatoria che Pouey-Mounou fa costantemente dialogare, attraverso precise contestualizzazioni storiche, con le riflessioni e i dibattiti dell'epoca, concernenti anche lo statuto antropologico e sociologico dell'uomo della Riforma. In particolare, attraverso i dati qui proposti e discussi con fine senso critico, emerge una elaborata rete di importanti interazioni fra tre nozioni centrali nel Tiers Livre: il paradosso, lo scandalo e la proprietà. Di fatto, per cercare di cogliere dall'interno le strutture diegetiche che reggono la narrazione del Tiers Livre, l'A. sviluppa le sue argomentazioni proprio partendo da queste tre nozioni, che fa costantemente dialogare con le relazioni intrattenute dai personaggi di questo libro 
con il mondo (contesto) in cui essi agiscono, con l'idea di libertà e di libero arbitrio soprattutto, sebbene tali idee siano rappresentate ed evocate attraverso quella costruzione anche parodica che viene eretta intorno al personaggio di Panurge. Le problematiche del paradosso e dello scandalo, come problematiche insite nell'epoca e centrali nella scrittura di Rabelais, diventano qui il tessuto di un discorso investigativo che tocca la dimensione filosofica, come pure i dibattiti contemporanei su tali due nozioni. Così, se la valutazione morale del personaggio di Panurge fa da motore per queste analisi, la filautia di questo stesso personaggio diventa campo di indagine sulla retorica del discorso, legata a delicate questioni sulla spiritualità che inquadra il Tiers Livre, a partire dalla nozione di scandalo, nozione di ascendenza biblica. Non è un caso, infatti, che l'A., sviluppando e facendo spesso convergere le sue riflessioni su un personaggio importante come Pantagruel, affermi che «l'impassibilité remarquable de Pantagruel tout au long du Tiers Livre, impassibilité parfaitement sérieuse et philosophiquement motivée pour le coup, engageait dès lors à suivre de plus près les lectures morales ou spirituelles du roman, et c'est ainsi que la propriété, le paradoxe et le scandale ont croisé les voies de la philautie», cioè le manifestazioni di una filautia da riconoscersi tutta in Panurge. In particolare, questo studio si divide in tre grandi sezioni principali. Nella prima l'A. si concentra sul significato e sull'intrepretazione delle metafore relative alle pietre e alle erbe, nella seconda - attraverso le interazioni fra i personaggi - sulle espressioni e sulle locuzioni avverbiali messe in campo dall'uno o dall'altro, relativamente alla nozione di proprietà. Infine, nella terza, le analisi interessano l'uso delle metafore, secondo una prospettiva analitica, appunto, prospettiva attraverso cui Pouey-Mounou tenta di costruire un itinerario critico complessivo intorno all'uso del discorso metaforico, cercando anche di ritracciare proprio secondo questo asse investigativo - un filo conduttore, continuativo e consecutivo, dai primi capitoli del Tiers Livre all'ultimo. Un'ampia bibliografia chiude questo pregiatissimo lavoro, che si raccomanda per la serietà e per l'importanza della documentazione discussa. 